\title{
ЦИФРОВАЯ ТРАНСФОРМАЦИЯ МАРКЕТИНГОВЫХ СТРАТЕГИЙ МАЛЫХ В2В КОМПАНИЙ (НА ПРИМЕРЕ СТРОИТЕЛЬНЫХ КОМПАНИЙ)
}

\author{
(c) 2021 Райтер Ксения Алексеевна \\ магистр экономики, аспирант \\ НИУ ВШЭ, Россия, Санкт-Петербург \\ E-mail: Ksenia.rayter@mail.ru
}

В статье рассматриваются вопросы цифровой интеграции в маркетинговых стратегиях малых B2B компаний. В связи с глобальным социально-экономическим кризисом, усиленным COVID-19, малые В2В компании стремительно теряют конкурентоспособность. Целью исследования является анализ предпосылок и процесса цифровой трансформации маркетинговых стратегий малых В2В компаний. Данные исследования были собраны методом углубленных интервью представителей российских малых (строительных) В2В компаний. Полученные данные могут быть использованы в малых В2В компаниях аналогичного профиля в разработке технологии формирования цифровой стратегии, и составления соответствующих научно-методических и практических рекомендаций в области инновационного развития малых В2В компаний.

Ключевые слова: цифровая трансформация, интернет-маркетинг, малые предприятия, В2В, маркетинговая стратегия, инновационный маркетинг, строительные компании.

\section{Введение}

В настоящее время малые В2В компании в России подвержены сильному экономическому и социальному влиянию, вызванному COVID-19. Во всем мире происходит цифровая трансформация спроса и предложения, услуги и товары также претерпевают изменения, выходя на новые онлайн рынки. В следствие чего малые В2В компании вынуждены следовать глобальным тенденциям цифровизации и перехода в онлайн пространство.

На конец 2019 года доля малых строительных компаний составляла около 12,7\% от всех малых предприятий, оборот которых колеблется в пределах 9,9\% [4].

В строительной отрасли высоких технологий очень важно переосмыслить бизнес-модели и архетипы предприятия в целом. В то же время экономический кризис, вызванный COVID-19, позволил выявить недостатки в управлении малыми строительными предприятиями, скрытые из-за общего роста строительного рынка, что позволило получать прибыль даже при неэффективном управлении. Переход потребителей в онлайн-пространство, социальные дистанции, увольнения или перевод работников на удаленный режим работы также заметно усложнили привычный режим работы как, в частности, малых строительных предприятий, так и малых В2В компаний в целом.
Изменения в потребительском спросе, предпочтениях и поведении потребителей диктуют новые правила выживания бизнеса. Несмотря на снятие многих ограничений для строительной отрасли, покупатели не спешат возвращаться к офлайн-покупкам. По данным Wunderman Thompson [22], количество офлайн-продаж B2B-компаний, к которым относятся малые строительные компании, сократилось с $44 \%$ до $16 \%$ во время пандемии.

Кризис - это прежде всего возможность для роста и развития компании [8]. В кризисных ситуациях компании обычно прибегают к сокращению своих бюджетов, начиная с сокращения маркетинговых бюджетов. Однако исследование [15] показало, что инвестирование в маркетинговый бюджет малых и средних компаний на одном и том же уровне в кризисные периоды приводит к полной окупаемости инвестиций, а также к дальнейшему росту продаж. Все это приводит к тому, что во время рецессии и коронавирусного кризиса МСП (малые строительные предприятия) должны внести изменения в свои маркетинговые стратегии.

Переход малых В2В предприятий на использование цифровых технологий в своей маркетинговой стратегии является наилучшим решением текущего социально-экономического кризиса и кризиса потребления, а также дает компаниям конкурентное преимущество за счет 
инновационного подхода к формированию их стратегий развития.

В статье под цифровыми технологиями понимаются большие данные, облачные вычисления, ІоТ (Интернет вещей), разработка платформ, искусственный интеллект, социальные и мобильные технологии [6, 19, 21].

\section{Литературный обзор}

В статье цифровые технологии рассматриваются как инструмент маркетинговых инноваций для малых В2В компаний, работающих в современных российских экономических условиях, в основном в Санкт-Петербурге. В связи с этим данный обзор посвящен четырем ключевым темам: теория инноваций и концепция стратегического управления, инновационный маркетинг, малые В2В предприятия и цифровая трансформация их маркетинговых стратегий.

Теоретические проблемы предпринимательства и эволюции социально-экономических систем затрагивались еще в начале прошлого века [18]. В целом стратегия представляет собой комбинацию методов конкуренции и процессов управления, направленных на удовлетворение потребностей потребителей и достижение организационных целей [20]. Стратегическое управление компанией предполагает ответы на следующие три вопроса: Чего мы хотим достичь в результате своей деятельности? Кто мы сейчас? Каков метод перехода компании из нынешнего состояния в то, которое обеспечит достижение целей [13]?

Кроме того, разработка стратегии компании по повышению конкурентоспособности организации возможна только на основе оценки предпринимательских возможностей. Для этого необходимо учитывать конкурентные возможности компании. Стратегические цели предприятия должны быть определены при использовании ключевых факторов успеха организации. В общем виде их можно разделить на четыре группы [7]:

- рост доли организации в инвестиционном секторе на товарном рынке;

- разработка и запуск нового продукта;

- рост продаж;

- получение предполагаемой прибыли.

Маркетинг и инновации - это единственные два фактора, которые вносят вклад в прибыль компании [9]. Маркетинг можно определить, как максимизацию прибыли за счет удовлетворения потребностей клиентов [2]. Инновационный маркетинг относится к понятию маркетинга, которое подразумевает, что компания должна постоянно совершенствовать свои продукты, а также формы и методы их продвижения и маркетинга. Инновационный маркетинг имеет два направления: маркетинг нового продукта и модернизация существующего продукта. Это означает, что инновационный маркетинг можно разделить на инновации в маркетинге и инновационный маркетинг [3].

Тенденции в маркетинге можно разделить на маркетинговую стратегию, цифровой маркетинг, инновации, ориентацию на клиента и «силу детализации» [10]. К сожалению, до кризиса с коронавирусом малые В2В компании все еще рассматривали цифровую трансформацию своих маркетинговых стратегий как издержки.

В настоящее время все еще существует много сомнений со стороны предпринимателей малых В2В компаний в процессе инвестирования в цифровую трансформацию. Большинство из них продолжают утверждать, что бюджетирование онлайн-маркетинга - это в первую очередь расходы компании, а не инвестиции [16]. Однако, если проводить оценку эффективности интернет-маркетинга в течение всего срока службы продукта, этого не происходит.

В то же время более половины владельцев и маркетологов опрошенных компаний не понимают алгоритмов внедрения интернетмаркетинга в структуру маркетинговой стратегии своей компании. Это приводит к интуитивному построению маркетинговых стратегий и их цифровизации [1].

Существует множество каналов продвижения, дающих положительные результаты для B2C, С2C или масс медиа, но в случае с малыми В2В компаниями стандартные методы продвижения не работают. Например, SMM или вирусный маркетинг как инструменты цифровизации маркетинговой стратегии компании определенно не подходят [5]. В то же время, например, после глобального экономического кризиса в 2008 году В2В-компании увеличили бюджетные ассигнования на интернет-маркетинг и прямой маркетинг, как онлайн, так и оффлайн [14]. Кроме того, В2В-МСП стали уделять больше внимания CRM (Управлению взаимоотношениями с клиентами) и социальным сетям [12], а также краудсорсингу [15] и бренд-менеджменту.

Затянувшийся кризис является хорошим источником для реализации новой политики 
«выживших» предприятий. Основополагающим фактором развития конкурентоспособности малых В2В компаний должно послужить определенное сочетание цифровой трансформации и разработки стратегического плана их развития. Стоит отметить, что периоды рецессии позволяют активным В2В-компаниям, в том числе строительным компаниям, увеличивать свои конкурентные преимущества, не сокращая свои маркетинговые бюджеты [17]. Таким образом, кризис, вызванный коронавирусом, побуждает малые В2В компании, особенно строительные компании, внедрять цифровые технологии в свои маркетинговые стратегии. Сфера применения цифровых технологий постоянно растет и меняется [11]. Поэтому до сих пор нет однозначного понимания эффективности использования тех или иных цифровых технологий в сфере В2B, а также алгоритма внедрения цифровизации в маркетинговые стратегии малых В2В-компаний.

\section{Методология}

В статье обосновывается необходимость внедрения цифровых технологий в сфере В2В как инструмента стратегического развития малых B2B-компаний. Кроме того, в статье представлены первые результаты исследования, посвященного выявлению наиболее эффективных цифровых технологий в российском В2В секторе (в основном Санкт-Петербурге). С целью разработки логической структуры углубленного интервью была проведена первая серия интервью с пятью представителями строительных малых предприятий России. Информаторами выступили представители российской строительной отрасли: генеральные директора и руководители отдела маркетинга.

В процессе исследования была получена и обработана следующая информация: тенденции, данные и мнения информантов об эффективности цифровизации в строительной отрасли. Полученные данные послужат источником для второй серии углубленных интервью, которые поспособствуют более глубокому пониманию влияния цифровых технологий на стратегический потенциал малых В2В компаний. Все интервью были проведены при личной встрече.

Для опроса представителей строительной отрасли об их осведомленности, мнениях и опыте был использован качественный метод исследования. Дополнительным критерием включения информантов в выборку стала ориентация компании на рынок В2B.

Для этого исследования наиболее интерес- ными вопросами являются следующие:

1. Используете ли вы цифровые технологии в своей компании? Если да, то как давно?

2. С какими цифровыми технологиями вы знакомы?

3. Какие цифровые технологии вы используете?

4. Вы больше сосредоточены на цифровизации бизнес-модели компании или операционной цифровизации?

5. Используете ли вы интернет-маркетинг?

6. Какие проблемы вы хотели бы решить с помощью цифровой трансформации?

7. Каких успехов или изменений вам удалось добиться за период цифровой трансформации?

8. Внедрили ли вы какие-либо специальные показатели для оценки цифровизации вашей компании? Если да, то какая динамика отслеживалась?

9. Какие цифровые технологии вы видите у конкурентов вашей компании?

10. С какими трудностями вы столкнулись в процессе цифровой интеграции?

11. Сколько времени потребовалось сотрудникам, чтобы адаптироваться к цифровой среде?

12. Хотели бы вы что-то изменить в своей текущей цифровой стратегии? Если да, то что?

13. Повлияла ли эпидемиологическая ситуация в стране и экономический кризис на использование цифровых технологий в вашей компании?

14. Оцените результаты цифровой трансформации в вашей компании от 1 до 10, где 10 - полностью решены все существующие проблемы, одновременно решены несколько неожиданных вопросов, стоящих перед компанией, не возникло трудностей в процессе внедрения; 1 - выбранные инструменты / стратегия не решили проблем и не принесли желаемого эффекта.

В процессе интервью информантам также были заданы соответствующие вопросы, чтобы прояснить восприятие цифровизации малых B2B компаний, а также уровень внедрения цифровых инструментов в сфере В2В.

\section{Полученные данные}

В течение интервью, как и ожидалось ранее, выяснилось, что представители малого В2В бизнеса слабо понимают концепцию, виды и инструменты цифровизации. Трое из пяти информантов заявили, что используют цифровые 
технологии уже более 10-15 лет. Однако, в процессе уточнения, какие цифровые технологии они знают, были названы только 1С Битрикс, веб-сайты, программы автоматизации, цифровая подпись и печать, а также электронное управление документами. Таким образом, перечисленные технологии можно отнести к беспроводным технологиям, и в соответствии с нашей классификацией, их можно отнести к типу цифровизации - Интернет вещей.

Два других информанта, отвечая на вопрос о продолжительности цифровой трансформации, отметили, что использование началось более 17 лет назад, как создание сайта - «онлайнвизитной карточки компании», но по сей день цифровая интеграция не завершена. Кроме того, в процессе интервью удалось составить таблицу 1 , отражающую цифровые технологии, используемые малыми В2В компаниями в России, по мнению информантов.

В соответствии с классификацией, используемой в данной работе, большинство перечисленных цифровых технологий, используемых малыми В2В компаниями в России, можно отнести к облачным вычислениям и Интернету вещей. Однако стоит также отметить, что в небольшой степени малые В2В компании используют практически все виды цифровых технологий, за исключением искусственного интеллекта.

Более того, неожиданным оказался тот факт, что информантами не было упомянуто 3D-моделирование как цифровая технология, которая, безусловно, используется большинством строительных компаний. Таким образом, можно сделать вывод, что представители малых В2В-компаний плохо осведомлены о типах цифровых технологий.

Обсуждая с представителями малого В2В бизнеса различия между цифровизацией бизнес-модели компании и операционной цифровизацией, были получены следующие результаты (схема 1).

Противоположную картину можно наблюдать при использовании интернет-маркетинга малыми B2B-компаниями в качестве одной из цифровых технологий. Представители двух компаний заявили, что они уже некоторое время используют интернет-маркетинг; представители трех других компаний в настоящее время не используют интернет-маркетинг. Также стоит отметить, что два представителя В2В МСП, которые не используют интернет-маркетинг, сообщили, что ими были предприняты попытки внедрения интернет-маркетинга в маркетинговые стратегии своих компаний. Однако они считают, что реализация стратегии интернет-маркетинга в рамках маркетинговых стратегий их компаний были безрезультатны из-за отсутствия осведомленности маркетологов компаний о релевантных В2В инструментах в области цифровизации (схема 2).

Говоря о решениях, которых представители строительной В2В отрасли хотели бы достичь с помощью цифровой трансформации, были получены довольно похожие ответы: быстрое взаимодействие с потребителями, рост компании на рынке, повышение узнаваемости бренда компании и рост продаж. В то же время все представители В2В МСП с сожалением отмечают, что единственным положительным изменением в цифровой трансформации стало расширение клиентской базы. Кроме того, ни одна из опрошенных компаний не ввела специальные показатели для оценки цифровизации компании.

Можно заключить, что компании не провели достаточно тщательного анализа своих конку-

Таблица 1. Цифровые технологии, используемые малыми В2В компаниями, по мнению представителей строительной отрасли в России.

\begin{tabular}{|l|l|}
\hline \multicolumn{1}{|c|}{ Тип цифровых технологий } & \multicolumn{1}{c|}{ Цифровые технологии } \\
\hline Маркетинг & $\begin{array}{l}\text { Вебсайт, почта, интернет-магазин, продвижение в социальных сетях, } \\
\text { SЕО-оптимизация, платные ресурсы для поиска заказчика }\end{array}$ \\
\hline Проектирование & Конструкторский софт, цифровые измерительные инструменты \\
\hline Коммуникации & $\begin{array}{l}\text { Телефония, приложения для аудио и видеосвязи с клиентами и между } \\
\text { сотрудниками, управленческая система контроля выполнения обяза- } \\
\text { тельств, облачные хранилища }\end{array}$ \\
\hline Оборудование & Контроль движения транспорта, лазерные построители \\
\hline Контроль финансовых ресурсов & Бухгалтерские программы, программы управленческого учета \\
\hline Контроль материальных ресурсов & Системы адресного хранения, расчёт пополняемых остатков \\
\hline Контроль кадровых ресурсов & $\begin{array}{l}\text { НR сайты и программы для найма персонала, системы расчета заработ- } \\
\text { ной платы }\end{array}$ \\
\hline
\end{tabular}


Таблица 2. Цифровые технологии, используемые малыми В2В компаниями в соответствии с представленной классификацией.

\begin{tabular}{|l|l|}
\hline \multicolumn{1}{|c|}{ Тип цифровых технологий } & \multicolumn{1}{|c|}{ Цифровые технологии } \\
\hline Социальные технологии & $\begin{array}{l}\text { Вебсайт, почта, интернет-магазин, продвижение в социальных сетях, } \\
\text { SЕО-оптимизация, платная реклама, НR сайты }\end{array}$ \\
\hline Мобильные технологии & Телефония \\
\hline Большие данные & Оптимизация \\
\hline Облачные вычисления & $\begin{array}{l}\text { Облачные хранилища, системы адресного хранения, управленческая } \\
\text { система контроля выполнения обязательств, расчёт пополняемых } \\
\text { остатков, системы расчета заработной платы }\end{array}$ \\
\hline Интернет вещей & $\begin{array}{l}\text { Приложения для аудио и видеосвязи с клиентами и между сотрудника- } \\
\text { ми, программы для найма персонала, контроль движения транспорта, } \\
\text { лазерные построители }\end{array}$ \\
\hline Разработка платформ & $\begin{array}{l}\text { Программное обеспечение для проектирования, бухгалтерское про- } \\
\text { граммное обеспечение, программы управленческого учета }\end{array}$ \\
\hline Искусственный интеллект & - \\
\hline
\end{tabular}

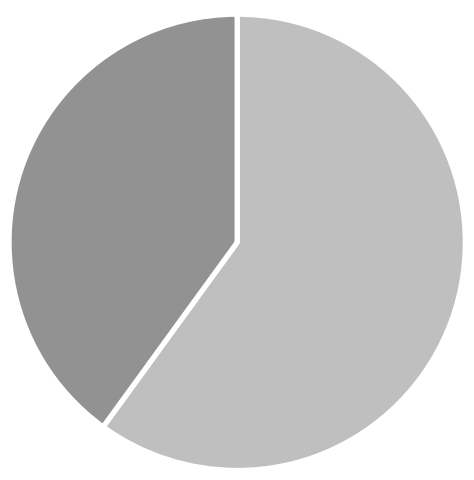

- Цифровизация бизнес модели компании = Операционная цифровизация

Схема 1. Частота использования малыми В2В компаниями цифровизации бизнес-модели компании и операционной цифровизации.

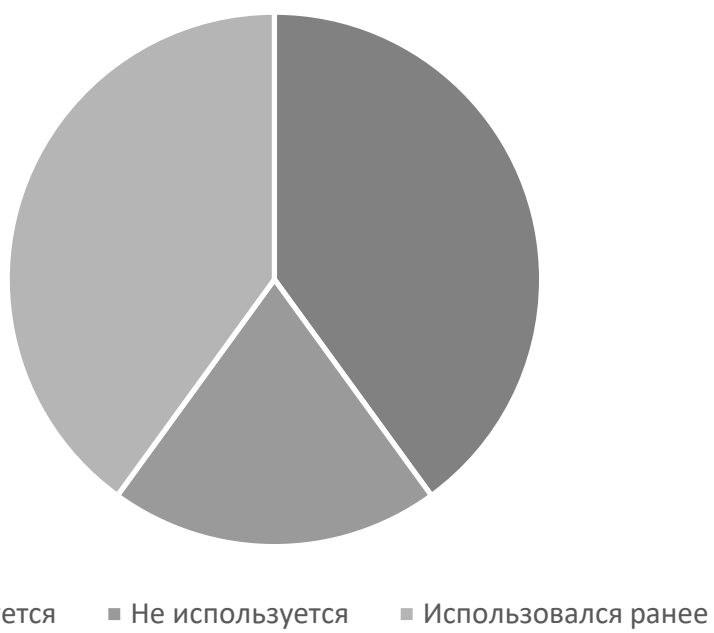

Схема 2. Использование интернет-маркетинга малыми В2В компаниями. 
рентов. Четверо из пяти представителей малых B2B компаний не смогли ответить на вопрос «Какие цифровые технологии вы видите у конкурентов вашей компании?». Ответ оставшегося информанта также был слишком общим: интернет-маркетинг, автоматизация процессов.

Отвечая на вопрос о трудностях, возникших в процессе цифровой трансформации, информанты упомянули временные и финансовые трудности, отсутствие положительного эффекта от внедрения. Также было отмечено, что основной проблемой является отсутствие окончательной реализации принятых решений и поставленных задач в связи с перечисленными проблемами.

Неожиданные результаты были получены при обсуждении вопроса о времени адаптации сотрудников к цифровой среде. Три представителя не отслеживали этот параметр и, более того, не считали это необходимым до проведенного интервью. Один информант утверждает, что адаптация сотрудников произошла менее чем за 2 месяца. Однако он не смог ответить на следующие вопросы: «Как контролировался процесс адаптации? И каким критерием измерялась успешная адаптация сотрудников?» Другой представитель В2В МСП с сожалением заявил, что их сотрудники не смогли адаптироваться, но никаких мер по содействию адаптации предпринято не было.

Следующий блок интервью был направлен на выяснение планов компаний о внесении каких-либо изменений в текущую цифровую стратегию компаний. Четверо из пяти инфор- мантов ответили на него почти одинаково, выразив запрос о будущем росте внедренных цифровых технологий. Однако один из представителей малых В2В компаний выразил обеспокоенность по поводу усиления цифровой трансформации компании. По его словам, для начала нужно разобраться в существующих инструментах цифровизации и в том, как они используются в сфере В2В.

Последним открытым вопросом интервью был вопрос: «Повлияла ли эпидемиологическая ситуация в стране и экономический кризис на использование цифровых технологий в вашей компании?». Все информанты в той или иной степени отметили ухудшение, вызванное пандемией COVID-19. Наблюдается стремительный спад продаж и рост коммуникации с помощью цифровых технологий, а не при личных встречах, как это чаще всего имело место ранее.

Интервью со всеми информантами завершилось просьбой оценить результаты цифровой трансформации в их компаниях. Количественные результаты оценки удовлетворенности цифровой трансформацией представителей малых В2В компаний можно увидеть на схеме 3.

На схеме 3 видно, что удовлетворенность цифровой трансформацией представителей малых В2В компаний не превышает 7 баллов из 10. Более того, средняя удовлетворенность (AS) цифровой трансформацией составляет всего 4,4 балла из 10.

$$
\mathrm{AS}=(7+5+5+3+2) \div 5=4.4
$$

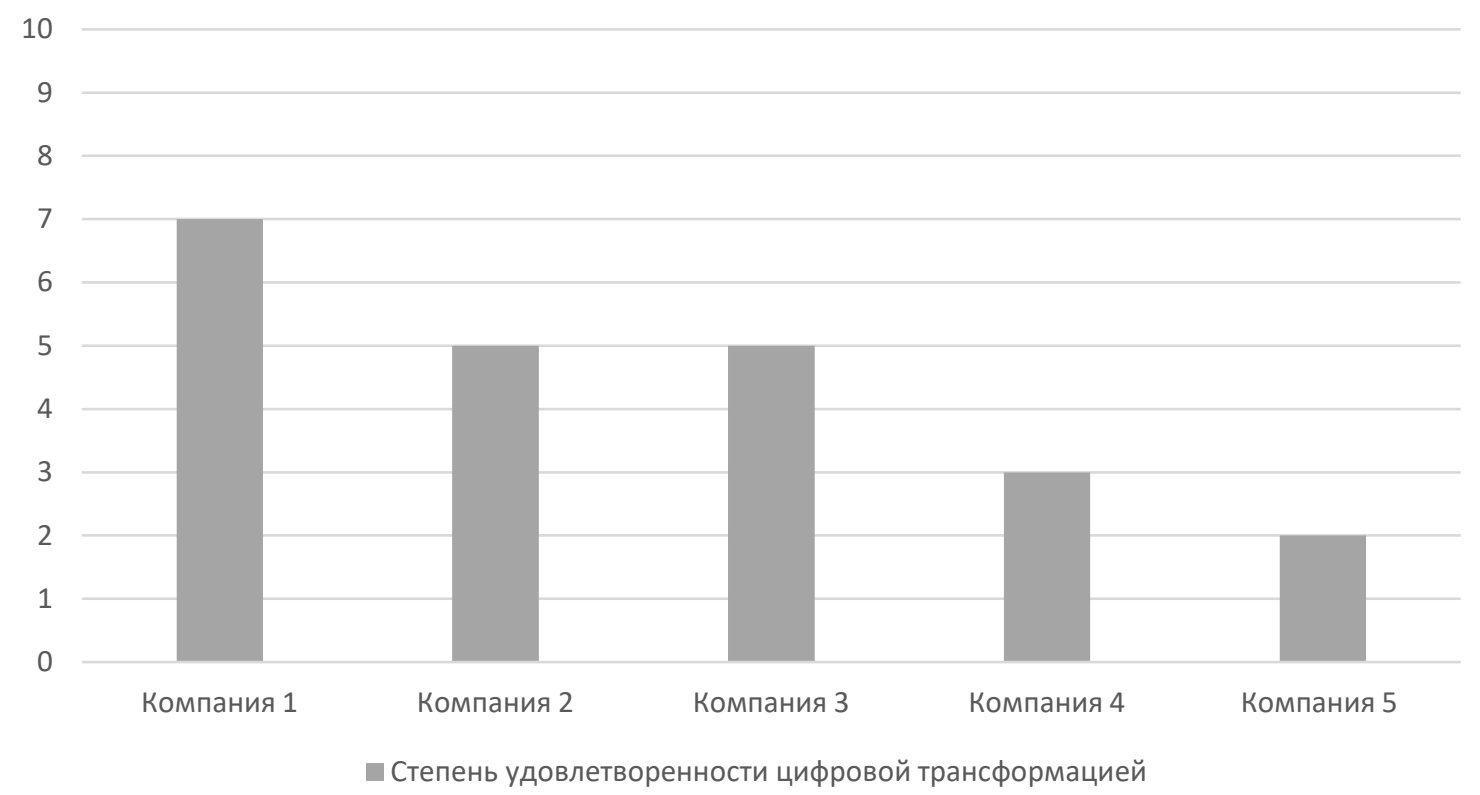

Схема 3. Удовлетворенность цифровой трансформацией представителей малых В2В компаний. 


\section{Выводы}

Проведя интервью с пятью представителями малых В2В компаний в России, можно сделать предварительный вывод, что полученные данные совпадают с представленным кратким обзором литературы. В процессе интервью были подняты вопросы об осведомленности представителей о типах цифровых технологий, получены мнения об их эффективности, а также собраны данные об их опыте цифровой трансформации и об изменениях, вызванных пандемией COVID-19. Кроме того, была получена количественная оценка удовлетворенности цифровой трансформацией представителей малых В2В компаний в компаниях информантов.

Полученные результаты можно сгруппировать следующим образом:

1. Низкая осведомленность представителей малых В2В компаний о цифровых технологиях, их видах и способах цифровой трансформации в маркетинговой стратегии компании.

2. Отсутствие плана цифровой трансформации для компании. Все изменения осуществляются интуитивно, предварительный анализ конкурентов, рынка и компании не проводится.

3. Отсутствие отслеживания процесса цифровой трансформации. Не были введены показатели для измерения эффективности цифровой трансформации исследованных малых В2В компаний, как и критерии для оценки адаптации сотрудников к цифровой среде.

4. Фокус на личном общении. Несмотря на пандемию COVID-19, представители строительных МСП по-прежнему предпочитают оффлайн взаимодействие на всех этапах работы с потребителями. На сегодняшний день в цифровизации бизнеса информанты видят скорее проблему, чем возможность для новых способов взаимодействия с клиентами, увеличения продаж с помощью цифровых технологий и повышения узнаваемости бренда.

5. Консерватизм. Страх перемен среди представителей малых В2В компаний также приводит к тому, что цифровая трансформация их компаний останавливается на этапе планирования, без фактической реализации.

Таким образом, все вышеперечисленные факторы приводят к низкому уровню удовлетворенности представителей малых В2В компаний процессом цифровой трансформации, что отражается в их средней оценке 4,4 балла из 10 баллов.

В соответствии с полученными данными представителям малых В2В компаний могут быть даны следующие рекомендации:

1. Провести обучение персонала по вопросам цифровой трансформации.

2. Провести анализ конкурентов и рынка компании и внутренний аудит компании.

3. Создать стратегию цифровой трансформации компании.

4. Ввести показатели для оценки эффективности цифровой трансформации компании.

5. Диверсифицировать взаимодействие с потребителями в онлайн-пространство.

Статья представляет собой первый этап по изучению цифровой трансформации среди российских малых В2В компаний. Ожидается, что дальнейшие исследования будут проведены в рамках еще одной серии углубленных интервью с другими представителями малых В2В компаний в России. Кроме того, после проведения серии качественных интервью и формирования гипотез ожидается проведение количественного онлайн-опроса среди более крупной репрезентативной выборки.

\section{Библиографический список}

1. Интернет-маркетинг 3.0: нет русской рулетке! / Зуев М. Б. [и др.]. 2-е изд.- СПб.: Питер, 2011. 208 с.

2. Кумар Н. Маркетинг как стратегия. Роль генерального директора в интенсивном развитии компании.- Москва: Претекст, 2008. 342 с.

3. Основы инновационного менеджмента: Учебное пособие / Под ред. Коссова В. В. - Москва: Магистр, 2009. 429 c.

4. Федеральная служба государственной статистики, Российский статистический ежегодник 2020. [Электронный ресурс] URL: https://rosstat.gov.ru/storage/mediabank/KrPEshqr/year_2020.pdf (дата обращения: 21.03.21)

5. Яковлев А.И., Ткачев, В.Г. Продвижение сайтов: Основы, секреты, трюки.-СПб.: БХВ-Петербург, 2013. 357 с.

6. Bharadwaj, A., El Sawy, O., Pavlou, P., \& Venkatraman, N. (2013). Digital Business Strategy: Toward a Next Generation of Insights. MIS Quarterly, 37(2), 471-482. Retrieved September 17, 2020, from http://www.jstor.org/ stable $/ 43825919$

7. Birnbaum, Bill. (2004). Strategic Thinking: A Four Piece Puzzle. Richmond, Texas: Douglas Mountain Publishing. 
8. Civi, E. (2013). Marketing strategies to survive in a recession. International Journal of Business and Emerging Markets, 5(3), 254-267. https://doi.org/10.1504/IJBEM.2013.054930

9. Drucker, P. F. (2000). The practice of management. Moscow: William.

10. Franklin, D, \& Andrew, A. (2013). World in 2050.-Per. with English.-Moscow: Eksmo.

11. Gokhberg L., Suslov A. B., Kovaleva G. G., Abdrakhmanova G., Leven E. Expenditure on the digital economy: what is it and how to measure it? / NRU Higher School of Economics. Series WP BRP «Science, Technology and Innovation». 2020. No. WP BRP 115/STI/2020.

12. Maciaszek L.A. (2008) Adaptive Integration of Enterprise and B2B Applications. In: Filipe J., Shishkov B., Helfert M. (eds) Software and Data Technologies. ICSOFT 2006. Communications in Computer and Information Science, vol 10. Springer, Berlin, Heidelberg. https://proxylibrary.hse.ru:2120/10.1007/978-3-540-70621-2_1

13. Mintzberg, H., Quinn, J.B., \& Ghoshal, S. (2001). Strategic process. SPb.: Peter.

14. Nasir, S. (2015). Customer relationship management strategies in the digital era. Hersey, PA: IGI Global.

15. Nickell, D., Rollins, M., \& Hellman, K. (2013). How to not only survive but thrive during recession: A multi-wave, discovery-oriented study. Journal of Business \& Industrial Marketing, 28(5), 455-461. https://proxylibrary.hse.ru: 2120/10.1108/08858621311330290

16. Percy, L., \& Elliot, R. (2008). Strategic planning of advertising companies-Per. with English. Moscow: publishing house Grebennikov.

17. Rizomyliotis I., Konstantoulaki K., Kostopoulos I. (2017) Business-to-Business Marketing Communication During Recession. In: Business-to-Business Marketing Communications. Palgrave Macmillan, Cham. https://proxylibrary. hse.ru:2120/10.1007/978-3-319-58783-7_2

18. Schumpeter, Y. A. (2007). Theory of economic development; capitalism, socialism and democracy.-M.: Eksmo.

19. Sebastian, I.M. \& Moloney, K.G. \& Ross, J.W. \& Fonstad, Nils \& Beath, Cynthia \& Mocker, Martin. (2017). How big old companies navigate digital transformation. MIS Quarterly Executive. 16. 197-213.

20. Thompson Jr., A., \& Strickland, A.J. (2006). Strategic management: concepts and situations for analysis, 12-th edition.- Per. with English.- Moscow: Publishing house «William».

21. Vial, G., (2019). Understanding Digital Transformation: A Review and Research Agenda. Journal of Strategic Information System, 28, 118-144.

22. Wunderman Thompson Commerce, The B2B future shopper report 2020. Available at: https://goo-gl.su/hyZGbP2 (accessed 18 September 2020). 